\title{
Treatment of Congenital Melanocytic Nevi With a Dual-Wavelengths Copper Vapor Laser: A Case Series
}

\author{
Igor V. Ponomarev ${ }^{* \oplus}$, Sergey B. Topchiy ${ }^{1}$, Alexandra E. Pushkareva ${ }^{2}{ }^{\circledR}$, Svetlana V. Klyuchareva ${ }^{3}{ }^{\circledR}$, Yury N. \\ Andrusenko $^{(\mathbb{D}}$ \\ ${ }^{1}$ P.N. Lebedev Physical Institute of the Russian Academy of Sciences, 53, Leninskiy Prospect, Moscow, 119991, Russian \\ Federation \\ ${ }^{2}$ Saint Petersburg National Research University of Information Technologies, Mechanics and Optics, 49, Kronverkskiy \\ Prospect, St. Petersburg, 197101, Russian Federation \\ ${ }^{3}$ Department of Dermatovenereology, I.I. Mechnikov North-Western State Medical University, 47, Piskarevkiy Prospect, St. \\ Petersburg, 195067, Russian Federation \\ ${ }^{4}$ Clinic of Aesthetic Medicine. Head of the Laser Department of the Health Institute, Kharkiv, 61000, Ukraine
}

\section{*Correspondence to}

Igor V. Ponomarev, PhD, Head of Laser Project P.N. Lebedev

Physical Institute of the Russian Academy of Sciences, 53, Leninskiy Prospect, Moscow, 119991, Russian Federation. Tel: +7-916-404-95-19; Email: iponom@okb.lpi.troitsk.ru

Published online February 14, 2021

\begin{abstract}
Introduction: Congenital melanocytic nevus $(\mathrm{CMN})$ is a severe challenge for dermatology. This pigmented skin lesion is undesirable for patients because of its localization in open areas of the body. Various visible and near-infrared laser systems and intense pulsed light (IPL) sources have been applied for $\mathrm{CMN}$ treatment. However, post-traumatic hyperpigmentation, structural changes, atrophy, and scarring due to non-specific thermal damage have been observed. Many patients have shown recurrence after treatment. Therefore, it highlights the need for testing new laser modalities for the management of CMN.

Methods: Two adult II Fitzpatrick phototype patients (a 55-year-old male and a 30-year-old female) with middle-sized facial CMN (on the forehead and lower eyelid) are presented. All patients were treated with dual-wavelength copper vapor laser (CVL) radiation at $511 \mathrm{~nm}$ and $578 \mathrm{~nm}$ wavelengths with a power ratio of 3:2. The average power was $0.7-0.85 \mathrm{~W}$ with an exposure time of 0.3 seconds. The spot size amounted to $1 \mathrm{~mm}$.

Results: Both patients showed complete resolution of CMN after CVL treatments. CMN became crusted within a few days after the laser treatment and peeled off within seven days. No recurrences were observed during the follow-up period up to 24 months.

Conclusion: The middle-sized CMN can be successfully treated with dual-wavelength CVL radiation. Keywords: Copper vapor laser; Melanocytic nevi; Selective pigmented treatment; Computer simulation; Blood vessel; Hyperpigmentation
\end{abstract}

\section{Introduction}

Patients often visit dermatologists to remove congenital melanocytic nevus $(\mathrm{CMN})$ in esthetical zones. This pigmented skin lesion is cosmetically undesirable for patients because of its localization in open areas of the body ${ }^{1-3}$ Therefore, the treatment of $\mathrm{CMN}$ is usually carried out not only for cosmetic reasons but also to reduce the risk of malignization. ${ }^{4}$

The main advantage of laser therapy compared to conventional methods for treating pigmented skin lesions is selective photothermolysis. Selective photothermolysis provides selective thermal necrosis of melanosomes without pronounced thermal deterioration of surrounding cells and collagen structures. Therefore, an excellent cosmetic result can be achieved with minimal risk of scar formation. Patients tolerate laser therapy well. Various visible and near-infrared laser systems (Q-switched lasers [ruby, alexandrite, second harmonic Nd: YAG laser with a wavelength of $532 \mathrm{~nm}$ and an Nd:YAG laser], pulsed dye lasers, copper and copper bromide vapor lasers), as well as intense pulsed light (IPL) pulsed light sources, have been applied. ${ }^{2,5-7}$

Unfortunately, post-traumatic hyperpigmentation, structural changes, atrophy, and scarring due to nonspecific thermal damage are observed in some cases. It can last up to several months. ${ }^{8}$

Therefore, it highlights the need for testing new laser modalities for the management of $\mathrm{CMN}$, and in the present study, we describe for the first time the CMN treatment with copper vapor laser (CVL). 


\section{Case Presentation \\ Laser Surgical Technique}

The study was performed in accordance with the Helsinki Protocol. The diagnosis is based on clinical features and dermatoscopy, and histological findings confirm it. The digital images of the CMN were obtained at all stages of the treatment.

After obtaining the patient's written informed consent, the laser treatment of CMN was performed using a CVL system (YAKHROMA-Med model developed at the Lebedev Physical Institute of the Russian Academy of Sciences). The total area of CMN was treated with dualwavelength CVL radiation at $511 \mathrm{~nm}$ and $578 \mathrm{~nm}$ with a power ratio of 3:2 in a pulsed mode. Laser radiation was focused on the patient's skin in a light spot with a diameter of $1 \mathrm{~mm}$. The distance between the centers of consequent light spots was estimated to be $1 \mathrm{~mm}$. The CVL pulse duration was $15 \mathrm{~ns}$, and the rep-rate was $16.6 \mathrm{kHz}$.

The laser irradiation power and exposure's minimal settings were selected, at which the pigment color changed (graying). The CVL treatment was moderately painful. No anesthesia was required.

Immediately after the procedure, the treatment area turned gray. A thin, dry, dark brown scab covered the treated area on the second - third day will fall off within 7-10 days, leaving the skin pink.

After the procedure, the skin was treated with a 0.05 $\%$ solution of chlorhexidine bigluconate; then, after the formation of the crusts, an epithelizing gel was applied two times a day until the crusts fell off.

The digital images of the CMN were obtained at all stages of the treatment. Sunscreens with SPF factors of at least 30 were recommended to protect the treated area.

\section{Case 1}

A 55-year-old Caucasian male patient presented with flat dark brownish medium-sized type $1 \mathrm{CMN}$ (30 mm in diameter) located in the forehead (Figure 1). The diagnosis of CMN was from birth and confirmed using dermoscopy and histologic data. The black dots/clumps concentrated in the middle of the involved area. The regular, uniform pigment showed a mesh structure. The histologic picture presented nevomelanocytes around the epidermal-dermal junction. In childhood, this patient was treated with liquid nitrogen. The treatment did not give the desired result.

The procedure was carried out using a laser handpiece with a spot size diameter of $1 \mathrm{~mm}$. The average power was chosen at $0.7-0.85 \mathrm{~W}$ with an exposure time of 0.3 seconds, which corresponded to a fluence level of 26-32 $\mathrm{J} / \mathrm{cm}^{2}$. Two sessions of the treatment with an interval of 1 month were performed. Immediately after the treatment, mild erythema was observed in the treated area. Within seven days after the treatment, crusts appeared in the treatment area. The crusts fell off on the $10^{\text {th }}-12^{\text {th }}$ day. Treatment results were evaluated one month after the second session. After checking the results of the treatment, the next treatment session was carried out.

\section{Case 2}

A healthy 30-year-old female presented with $\mathrm{CMN}$ on her left lower eyelids, which had been present from her childhood. CMN was a brown color measuring $10 \mathrm{~mm}$ in diameter (Figure 2, left). The diagnosis of CMN was from early childhood and confirmed with dermoscopic and histologic data, no melanoma in history or relatives. The treatment was performed by CVL radiation at $511 \mathrm{~nm}$ and $578 \mathrm{~nm}$ wavelengths with a power ratio of 3:2. The average power was chosen at $0.8 \mathrm{~W}$ with an exposure time of $0.3 \mathrm{~s}$. Three laser treatment sessions with an interval of 1 month were needed for the complete clearance of the lesions with minimal side effects and without deformity of the eyelid ocular injuries and relapses after the CVL treatment.

\section{Results}

The male patient showed complete resolution of CMN after two dual-wavelengths CVL treatments and the female after three CVL treatments. There was no bleeding during the procedure and after the laser treatment. Small erythema developed 15 minutes after the CVL treatment. After the healing of the treated area, complete CMN regression was achieved. The healing time lasted up to 3

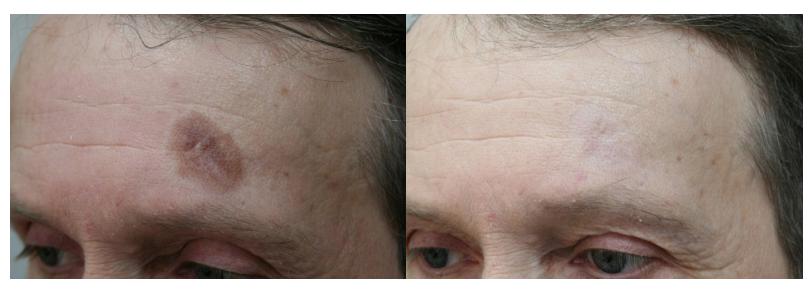

Figure 1. A 55-Year-Old Patient With CMN Before the Treatment (photo on the left) and 3 Months After the 2 Dual-Wavelengths CVL Treatment With A Power Ratio of 3:2 at Wavelengths of $511 \mathrm{~nm}$ and $578 \mathrm{~nm}$ (photo on the right), II skin phototype. The average power of the CVL was $0.8 \mathrm{~W}$; the exposure time was 0.3 seconds. $\mathrm{a}$ - before, $\mathrm{b}-5$ months after the second CVL treatment.

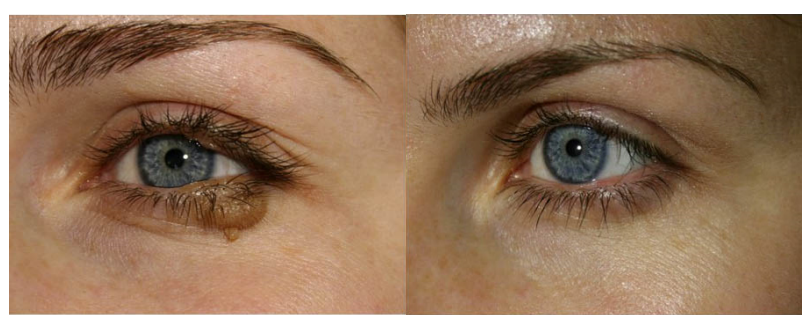

Figure 2. A 30-Year-Old Female With CMN Before the Treatment (photo on the left) and 4 Months After the 3 Dual-Wavelengths CVL Treatment With a Power Ratio of 3:2 at Wavelengths of $511 \mathrm{~nm}$ and $578 \mathrm{~nm}$ (photo on the right), II skin phototype. The average power of the CVL was $0.8 \mathrm{~W}$; the exposure time was $0.3 \mathrm{~s}$. $\mathrm{a}$ - before, $\mathrm{b}-4$ months after three sessions of the CVL treatment. 
weeks. No recurrences were observed during the followup period up to 24 months after the treatment.

\section{Discussion}

Our case study described for the first time the successful CMN treatment, without early and remote side effects, with two to three CVL sessions. Different laser systems and their combinations have been tried for CMN treatment with various successes within the last decades. Ablative lasers $\left(\mathrm{CO}_{2}\right.$ and Er:YAG) demonstrated a high risk of scarring. ${ }^{9}$

The introduction of Q-switched ruby, alexandrite, and Nd:YAG lasers made it possible to treat $\mathrm{CMN}$ with a lower rate of recurrences and complications, but the results were not permanent. All CMN patients treated with the ruby laser showed a partial response, and re-pigmentation occurred after several months. ${ }^{10}$

A combination of ablative lasers and Q-switched selective lasers was applied to better clearance and decrease the recurrence rate. Nevertheless, the recurrence rate of up to $82 \%$ was obtained one year after CMN treatment with IPL alone and its combination with the Er:YAG laser. ${ }^{11}$

Reported results of the CMN treatment are demonstrated in Table 1.

Histological studies showed that recurrence after CMN treatment with Q-switched ruby and Nd:YAG lasers connected with incomplete destruction of all nevomelanocytes. ${ }^{13}$

It is the reason for choosing a laser with maximum pigment selectivity for the management of CMN. The use of dual-wavelength CVL radiation, which corresponds to the high absorption of melanin at $511 \mathrm{~nm}$ and coincides with the local maximum absorption band of oxyhemoglobin at $578 \mathrm{~nm}$, can be useful for the CMN treatment.

The histological data of pigment destruction in the epidermis after the pulsed dye laser treatment with different wavelengths $(504,590,694,720,750 \mathrm{~nm})$ demonstrated the maximum selectivity and the most pigment-specific injury at a wavelength of $504 \mathrm{~nm}$, which is close to the green wavelength $511 \mathrm{~nm}$ of the CVL. ${ }^{14}$ Green CVL output at $511 \mathrm{~nm}$ was successfully used to treat epidermal pigmented skin lesions. ${ }^{15}$

An essential condition for laser selectivity is choosing the optimal laser pulse duration. The use of laser radiation with pulse duration, not exceeding the thermal relaxation time of the target chromophore unit, will minimize the surrounding tissue's thermal damage. Thermal relaxation time is determined by the size of the target chromophore unit. The CMN presents both isolated pigmented melanosome cells (size about $7 \mu \mathrm{m}$ and thermal relaxation time not exceeding $1 \mu \mathrm{s}$ ) and clusters (nests, conglomerates) consisting of pigment cells (cluster size and thermal relaxation time are about $100 \mu \mathrm{m}$ and $10 \mathrm{~ms}$ respectively). ${ }^{5}$ Therefore, to ensure heating selectivity, an ideal laser for the CMN treatment should act with both short nanosecond pulses and long millisecond pulses.

This mode of exposure provides the CVL. Each CVL pulse has a duration of 20 nanoseconds and a peak power of up to several $\mathrm{kW}$.

Optical coherence tomography data indicate up to two times increased vascularization in the area of CMN. ${ }^{16}$ The induction of melanogenesis by endothelial cells indicates the advisability of remodeling of the vascular bed associated with hyperpigmentation to prevent CMN relapsing. ${ }^{17}$ Yellow CVL radiation at $578 \mathrm{~nm}$ can be applied for selective heating of the dysplastic vessels in the CMN area, ${ }^{18,19}$ which demonstrates increased vascularization. It provides the remodeling of the vascular bed associated with the induction of melanogenesis by endothelial cells to prevent recurrences.

We relate our clinical results obtained by the dualwavelength CVL treatment of CMN to the high selectivity of pigment heating and remodeling of the involved vascular bed.

\section{Conclusion}

In summary, this is the first experience showing that the dual-wavelength CVL radiation with a power ratio of 3:2 at wavelengths of $511 \mathrm{~nm}$ and $578 \mathrm{~nm}$ is safe and effective for treating $\mathrm{CMN}$, especially in the periorbital region.

Additional studies are required to determine the optimal green/yellow ratio of the CVL power for different types and colors of the CMN, associated with the level of melanin content and the depth of pigment-containing cells. The CVL treatment of CMN makes possible individual adjustment of the laser settings by changing the green/yellow ratio depending on the color, pigmentation depth, and skin phototypes.

\section{Ethical Considerations}

Written informed consent was obtained from the patients before the treatment.

Table 1. Results of the CMN Treatment With Different Laser Systems

\begin{tabular}{|c|c|c|c|c|c|}
\hline Laser Type & Number of Treatments & CMN Size & Results & Side Effects & Ref. \\
\hline Q-switched Nd:YAG & $2-3$ & $<10 \mathrm{~mm}$ & $\begin{array}{l}39.8 \% \text { of } \mathrm{CMN} \text { were } \\
\text { completely removed }\end{array}$ & Bleeding & 12 \\
\hline Q-switched Ruby & $2-8$ & $1.5-19.9 \mathrm{~cm}$ & $100 \%$ recurrence & Bleeding & 10 \\
\hline $\begin{array}{l}\text { Er: YAG+IPL } \\
\text { IPL alone }\end{array}$ & $\begin{array}{c}4.7 \\
10.5\end{array}$ & $1.5-19.9 \mathrm{~cm}$ & $\begin{array}{l}82.4 \% \\
\text { recurrence }\end{array}$ & $\begin{array}{l}\text { Scaring } \\
\text { Bleeding }\end{array}$ & 11 \\
\hline
\end{tabular}




\section{Conflict of Interests}

The authors declare no conflict of interest.

\section{References}

1. Magaña M, Sánchez-Romero E, Magaña P, Beck-Magaña A, Magaña-Lozano M. Congenital melanocytic nevus: two clinicopathological forms. Am J Dermatopathol. 2015;37(1):31-37. doi: 10.1097/DAD.0000000000000183.

2. Alster TS, Lupton JR. Laser therapy for cutaneous hyperpigmentation and pigmented lesions. Dermatol Ther. 2001;14(1):46-54. doi: 10.1046/j.15298019.2001.014001046.x.

3. Fahradyan A, Wolfswinkel EM, Tsuha M, Reinisch JF, Magee W 3rd, Hammoudeh JA, et al. Cosmetically challenging congenital melanocytic nevi. Ann Plast Surg. 2019;82(5S Suppl 4):S306-S309. doi: 10.1097/sap.0000000000001766.

4. Rayala BZ, Morrell DS. Common skin conditions in children: congenital melanocytic nevi and infantile hemangiomas. FP Essent. 2017;453:33-37.

5. Sardana K, Chakravarty P, Goel K. Optimal management of common acquired melanocytic nevi (moles): current perspectives. Clin Cosmet Investig Dermatol. 2014;7:89103. doi: 10.2147/CCID.S57782.

6. Eggen CAM, Lommerts JE, van Zuuren EJ, Limpens J, Pasmans SGM, Wolkerstorfer A. Laser treatment of congenital melanocytic naevi: a systematic review. $\mathrm{Br} J$ Dermatol. 2018;178(2):369-383. doi: 10.1111/bjd.16094.

7. Al-Hadithy N, Al-Nakib K, Quaba A. Outcomes of 52 patients with congenital melanocytic naevi treated with UltraPulse carbon dioxide and frequency doubled Q-switched Nd-Yag laser. J Plast Reconstr Aesthet Surg. 2012;65(8):1019-1028. doi: 10.1016/j.bjps.2012.03.003.

8. Bhatt N, Alster TS. Laser surgery in dark skin. Dermatol Surg. 2008;34(2):184-195. doi: 10.1111/j.15244725.2007.34036.x.

9. Bray FN, Shah V, Nouri K. Laser treatment of congenital melanocytic nevi: a review of the literature. Lasers Med Sci. 2016;31(1):197-204. doi: 10.1007/s10103-015-1833-3.

10. Helsing P, Mørk G, Sveen B. Ruby laser treatment of congenital melanocytic naevi-a pessimistic view. Acta Derm Venereol. 2006;86(3):235-237. doi: 10.2340/00015555-0041.

11. Lee MS, Jun HJ, Cho SH, Lee JD, Kim HS. Intense pulsed light alone and in combination with Erbium YttriumAluminum-Garnet laser on small-to-medium sized congenital melanocytic nevi: single center experience based on retrospective chart review. Ann Dermatol. 2017;29(1):39-47. doi: 10.5021/ad.2017.29.1.39.

12. Kim YJ, Whang KU, Choi WB, Kim HJ, Hwang JY, Lee $\mathrm{JH}$, et al. Efficacy and safety of 1,064 nm Q-switched Nd:YAG laser treatment for removing melanocytic nevi. Ann Dermatol. 2012;24(2):162-167. doi: 10.5021/ ad.2012.24.2.162.

13. Grevelink JM, van Leeuwen RL, Anderson RR, Byers HR. Clinical and histological responses of congenital melanocytic nevi after single treatment with Q-switched lasers. Arch Dermatol. 1997;133(3):349-353. doi: 10.1001/ archderm.1997.03890390089012.

14. Sherwood KA, Murray S, Kurban AK, Tan OT. Effect of wavelength on cutaneous pigment using pulsed irradiation. J Invest Dermatol. 1989;92(5):717-720. doi: 10.1016/0022202X(89)90187-5.

15. Somyos K, Boonchu K, Somsak K, Panadda L, Leopairut J. Copper vapour laser treatment of café-au-lait macules. Br J Dermatol. 1996;135(6):964-968. doi: 10.1046/j.13652133.1996.d01-1103.x.

16. Ulrich M, Themstrup L, de Carvalho N, Manfredi M, Grana C, Ciardo S, et al. Dynamic optical coherence tomography in dermatology. Dermatology. 2016;232(3):298-311. doi: $10.1159 / 000444706$.

17. Regazzetti C, De Donatis GM, Ghorbel HH, CardotLeccia N, Ambrosetti D, Bahadoran P, et al. Endothelial cells promote pigmentation through endothelin receptor $\mathrm{B}$ activation. J Invest Dermatol. 2015;135(12):3096-3104. doi: 10.1038/jid.2015.332.

18. Klyuchareva SV, Ponomarev IV, Pushkareva AE. Numerical modeling and clinical evaluation of pulsed dye laser and copper vapor laser in skin vascular lesions treatment. J Lasers Med Sci. 2019;10(1):44-49. doi: 10.15171/ jlms.2019.07.

19. Ponomarev IV, Topchiy SB, Kazaryan MA, Pushkareva AE, Klyuchareva SV. Numerical simulation optimization of selective heating of blood vessels in "Port-Wine stains" under laser irradiation in various modes. Bull Lebedev Phys Inst.2018;45(7):204-208. doi: 10.3103/S1068335618070035. 